Research Article

\title{
Analysis of the ergosterol biosynthesis pathway cloning, molecular characterization and phylogeny of lanosterol $14 \alpha$-demethylase (ERG11) gene of Moniliophthora perniciosa
}

Geruza de Oliveira Ceita ${ }^{1,4}$, Laurival Antônio Vilas-Boas², Marcelo Santos Castilho ${ }^{3}$, Marcelo Falsarella Carazzolle ${ }^{5}$, Carlos Priminho Pirovani ${ }^{6}$, Alessandra Selbach-Schnadelbach ${ }^{4}$, Karina Peres Gramacho ${ }^{7}$, Pablo Ivan Pereira Ramos ${ }^{4}$, Luciana Veiga Barbosa ${ }^{4}$, Gonçalo Amarante Guimarães Pereira ${ }^{5}$ and Aristóteles Góes-Neto ${ }^{1}$

${ }^{1}$ Laboratório de Pesquisa em Microbiologia, Departamento de Ciências Biológicas, Universidade Estadual de Feira de Santana, Feira de Santana, BA, Brazil.

${ }^{2}$ Centro de Ciências Biológicas, Departamento de Biologia Geral, Universidade Estadual de Londrina, Londrina, PR, Brazil.

${ }^{3}$ Laboratório de Bioinformática e Modelagem Molecular, Departamento do Medicamento, Faculdade de Farmácia, Universidade Federal da Bahia, Salvador, BA, Brazil.

${ }^{4}$ Laboratório de Biologia Molecular, Instituto de Biologia, Departamento de Biologia Geral, Universidade Federal da Bahia, Salvador, BA, Brazil.

${ }^{5}$ Laboratório de Genômica e Proteômica, Departamento de Genética e Evolução, Universidade Estadual de Campinas, Campinas, SP, Brazil.

${ }^{6}$ Centro de Biotecnologia e Genética, Departamento de Ciências Biológicas, Universidade Estadual de Santa Cruz, Ilhéus, BA, Brazil.

${ }^{7}$ Laboratório de Fitopatologia Molecular, Centro de Pesquisas do Cacau, Ilhéus, BA, Brazil.

\begin{abstract}
The phytopathogenic fungus Moniliophthora perniciosa (Stahel) Aime \& Philips-Mora, causal agent of witches' broom disease of cocoa, causes countless damage to cocoa production in Brazil. Molecular studies have attempted to identify genes that play important roles in fungal survival and virulence. In this study, sequences deposited in the M. perniciosa Genome Sequencing Project database were analyzed to identify potential biological targets. For the first time, the ergosterol biosynthetic pathway in $M$. perniciosa was studied and the lanosterol $14 \alpha$-demethylase gene (ERG11) that encodes the main enzyme of this pathway and is a target for fungicides was cloned, characterized molecularly and its phylogeny analyzed. ERG11 genomic DNA and CDNA were characterized and sequence analysis of the ERG11 protein identified highly conserved domains typical of this enzyme, such as SRS1, SRS4, EXXR and the heme-binding region (HBR). Comparison of the protein sequences and phylogenetic analysis revealed that the $M$. perniciosa enzyme was most closely related to that of Coprinopsis cinerea.
\end{abstract}

Keywords: Basidiomycota, fungus, ergosterol, Theobroma cacao.

Received: April 11, 2014; Accepted: June 4, 2014.

\section{Introduction}

Cocoa (Theobroma cacao L.) cultivation has suffered significant production losses because of diseases that affect its crops (Pereira et al., 1989; Purdy and Schimidt, 1996; Evans, 2007). Among the main pathogens that cause dis-

Send correspondence to Aristóteles Góes-Neto. Laboratório de Pesquisa em Microbiologia, Departamento de Ciências Biológicas, Universidade Estadual de Feira de Santana, Avenida Transnordestina, 44036-900 Feira de Santana, BA, Brazil. E-mail: arigoesneto@pq.cnpq.br. eases in cocoa, the basidiomycete Moniliophthora perniciosa (Stahel) Aime \& Philips-Mora has received considerable attention because it is the causal agent of witches' broom disease (Griffith et al., 1994, 2003; Aime and Phillips-Mora, 2005).

Moniliophthora perniciosa has biotrophic and saprophytic stages (Griffith et al., 2003; Meinhardt et al., 2006). The biotrophic stage is characterized by basidiospore infection in meristematic regions that leads to hypertrophy of infected tissues and the proliferation of abnormal axillary 
branches known as green brooms. In the saprophytic stage, basidiomata that sporulate on plant material are generated and dry brooms occur as a result of cell death in infected tissues (Ceita et al., 2007), one of the characteristic symptoms of this disease. Oxalate production and calcium oxalate crystal accumulation also play a role in the pathogenesis of witches' broom disease (Rio et al., 2008).

The action of azole-group antifungals has created new perspectives for controlling witches' broom in cocoa trees and has highlighted the importance of analyzing ergosterol biosynthesis in M. perniciosa in order to develop specific inhibitors of this pathway (McQuilken and Rudgard, 1988; Mota et al., 2010). To accomplish this, it is essential to study the development of the disease from molecular and biochemical perspectives. In this sense, the sequencing of the $M$. perniciosa genome has led to the discovery of genes that are essential for metabolism and development in this species and has resulted in several studies that have focused on gene expression analysis (Formighieri et al., 2008; Mondego et al., 2008).

Analyses of the biotrophic and saprophytic stages of M. perniciosa revealed high gene expression levels of the cytochrome P450 superfamily, this altered expression included lanosterol $14 \alpha$-demethylase, a key enzyme in the ergosterol biosynthetic pathway in fungi that is a target for antifungals and is encoded by the ERG11 gene (Rincones et al., 2008; Pires et al., 2009). Lanosterol $14 \alpha$-demethylase belongs to the CYP51 family of the cytochrome P450 superfamily, which is notable for being the only cytochrome P450 family that is present in all biological kingdoms (Waterman and Lepesheva, 2005; Lepesheva and Waterman, 2007).

Antifungals that affect the ergosterol biosynthetic pathway have been used for decades. Azole-group antifungals are potentially useful disease-modulating agents because of their specific binding to lanosterol $14 \alpha$-demethylase and their selective inhibition of the removal of the methyl group by this enzyme, which leads to the accumulation of unsaturated intermediates and to the depletion of ergosterol (Hof, 2001; Carrillo-Muñoz et al., 2006; Sheng et al., 2009). Ergosterol is an important component of the fungal cell membrane that regulates membrane fluidity and permeability (Barrett-Bee and Dixon, 1995; Lees et al., 1995; Veen and Lang, 2005).

The ERG11 gene sequences of a wide range of fungal species that are harmful to agricultural crops and human health have been determined and characterized. These species include Antrodia cinnamomea (Lee et al., 2010), Aspergillus fumigatus (Mellado et al., 2001; Warrilow et al., 2010), Botrytis cinerea (Albertini et al., 2002), Candida albicans (Lai and Kirsch, 1989; Park et al., 2011), Candida glabrata (Kairuz et al., 1994), Cryptococcus neoformans (Revankar et al., 2004; Sheng et al., 2009), Penicillium digitatum (Zhao et al., 2007), Malassezia globosa (Kim et al., 2011), Monilinia fructicola, previ- ously known as Monilia fructicola (Luo and Schnabel, 2008), Pneumocystis carinii (Morales et al., 2003), Saccharomyces cerevisiae (Kalb et al., 1987), Oculimacula yallundae, previously known as Tapesia yallundae (Wood et al., 2001), Uncinula necator (Délye et al., 1997) and Ustilago maydis (Lamb et al., 1998). The ERG11 gene also has an important role in the steroid biosynthetic pathways of bacteria, plants and mammals in which its gene product has the same metabolic role as its fungal counterpart (Rozman et al., 1996; Bak et al., 1997; Bellamine et al., 1999; Jackson et al., 2003; Pietila et al., 2006).

In this report, we describe the first identification, molecular characterization, cloning and phylogenetic analysis of the ERG11 gene that encodes lanosterol $14 \alpha$-demethylase, an enzyme that is essential for the survival and pathogenicity of M. perniciosa. The results presented here should be useful in identifying antifungal drugs active against this enzyme and, consequently, in controlling witches' broom disease in cocoa trees.

\section{Materials and Methods}

\section{Ergosterol pathway in Moniliophthora perniciosa and sequence analyses}

The sequences examined in this work were retrieved from the Moniliophthora perniciosa Genome Sequencing Project database (www.lge.ibi.unicamp.br/vassoura/) and were used as the primary source for identifying genes of the ergosterol biosynthetic pathway in M. perniciosa. With this database, it was possible to obtain the genomic consensus sequences that were predicted to encode the main enzymes of this pathway, such as lanosterol $14 \alpha$-demethylase, and to compares these sequences with those from other organisms.

The genes were accurately analyzed using ab initio programs for gene prediction, such as AUGUSTUS (Stanke et al., 2006) and GeneMark (Ter-Hovhannisyan et al., 2008). These analyses were then combined with the Basic Local Alignment Search Tool (BLAST) algorithm (Altschul et al., 1990) to align the sequences with those of phylogenetically related species. This approach allowed the identification of expressed regions, the presence and number of introns, and of regions bordering the ERG11 gene. BioEdit software (v. 7.1.3) (Hall, 1999) was used to align the predicted genomic DNA and cDNA sequences with sequences determined by sequencing.

Signal peptide prediction was done using SignalIP 4.0 software (Petersen et al., 2011), and probable transmembrane domains were determined using the Phobius program (Kall et al., 2007). The ProtoParam tool was used to analyze the physical and chemical parameters of the proteins, such as the theoretical isoelectric points (pIs) and molecular masses (Gasteiger et al., 2005). Additionally, the conserved domains, functional sites and protein family 
were determined using PROSITE software (Sigrist et al., 2009).

The lanosterol $14 \alpha$-demethylase sequences of other organisms were identified in GenBank and analyzed using the Protein BLAST (Blastp) tool. The M. perniciosa sequence was used as a reference (Table 1).

\section{M. perniciosa strain and culture conditions}

The 948F strain of $M$. perniciosa (Ilhéus, Bahia, Brazil), which was kindly provided by the Phytopathology Laboratory at the Cocoa Research Center (Centro de Pesquisas do Cacau da Comissão Executiva do Plano da Lavoura Cacaueira - CEPEC/CEPLAC, Ilhéus, Bahia, Brazil), was used in the experimental procedures. The strain was inoculated in Petri dishes containing Sabouraud agar solid medium (Sigma-Aldrich) to maintain mycelial discs and in YPD liquid medium (1\% yeast extract, $1 \%$ peptone and $2 \%$ dextrose) (Sigma-Aldrich) and incubated statically at $27^{\circ} \mathrm{C}$ for 15 days to obtain an adequate mycelial mass for genomic DNA and total RNA extraction.

\section{Genomic DNA extraction}

Total DNA was extracted from $M$. perniciosa mycelia according to the protocol described by Raeder and Broda (1985). The DNA concentration was determined spectrophotometrically (Novaspec II, Pharmacia Biotech) and the quality and quantity of the extracted DNA were analyzed in $1 \%$ agarose gels.

\section{RNA isolation and reverse transcription}

Total mycelial RNA was obtained using a RiboPure kit (Ambion) according to the manufacturer's recommendations. The first cDNA strand was produced from 1-3 $\mu \mathrm{g}$ of total RNA using the RevertAid H Minus M-MuLV Reverse Transcriptase kit (Fermentas Life Sciences) according to the manufacturer's recommendations.

\section{Primer design and amplification conditions}

Specific primers for PCR and RT-PCR were designed based on the predicted ERG11 sequence in M. perniciosa (Figure S1). We aimed to obtain complete fragments of DNA and cDNA (1,668 bp) using the primers LanFNcoIfull and LanRXhoI. A fragment (1,496 bp) that lacked the signal peptide was obtained using the primers LanFNheIfull and LanRNheI. A fragment (1,400 bp) that lacked the first transmembrane helix was obtained with the primers LanFNheIdel1ahel and LanRNheI. Lastly, a fragment $(1,316 \mathrm{bp})$ that lacked the regions corresponding to the first and second transmembrane helices was constructed using the primers LanFNheIdel2ahel and LanRNheI (Table 2).

Amplifications were done using a Mastercycler Gradient thermocycler (Eppendorf) with variable annealing temperatures. The following program was used: $3 \mathrm{~min}$ at $94{ }^{\circ} \mathrm{C}, 35$ cycles that included $1 \mathrm{~min}$ at $95^{\circ} \mathrm{C}, 1 \mathrm{~min}$ at $60^{\circ} \mathrm{C}$ and $2 \mathrm{~min}$ at $72{ }^{\circ} \mathrm{C}$ and a final extension of $5 \mathrm{~min}$ at $72^{\circ} \mathrm{C}$.

Table 1 - CYP51 proteins deposited in GenBank used for sequence and phylogenetic analyses.

\begin{tabular}{|c|c|c|c|}
\hline Organism & Accession number & Length (aa) & E-value \\
\hline Aspergillus fumigatus & ACF17705.1 & 515 & $5 e^{143}$ \\
\hline Candida albicans & AAF00603.1 & 528 & $2 \mathrm{e}^{-135}$ \\
\hline C. dubliniensis $\mathrm{CD} 36$ & CAX41448.1 & 528 & $5 \mathrm{e}^{-138}$ \\
\hline C. glabrata & AAX39317.1 & 533 & $5 \mathrm{e}^{-139}$ \\
\hline C. tropicalis & AAX39316.1 & 528 & $7 \mathrm{e}^{-135}$ \\
\hline Coprinopsis cinerea & AAU01159.1 & 531 & 0 \\
\hline Cryptococcus neoformans var. neoformans & AAF35366.1 & 550 & 0 \\
\hline C. gattii & AEQ63274.1 & 550 & 0 \\
\hline Homo sapiens & NP_000777.1 & 509 & $1 \mathrm{e}^{-196}$ \\
\hline Kluyveromyces lactis & CAG99196.1 & 527 & $9 \mathrm{e}^{-137}$ \\
\hline Moniliophthora perniciosa & JX915631 & 555 & $一$ \\
\hline Monilinia fructicola & ACF06200.1 & 522 & $3 \mathrm{e}^{-130}$ \\
\hline Mus musculus & NP_064394.2 & 503 & $5 e^{-96}$ \\
\hline Mycobacterium tuberculosis & САВ02394.1 & 451 & $8 \mathrm{e}^{-161}$ \\
\hline Pneumocystis carinii & AAO38776.1 & 513 & $5 \mathrm{e}^{-148}$ \\
\hline Phanerochaete chrysosporium & AAU01160.1 & 540 & 0 \\
\hline Pichia kudriavzevii & ABY26735.1 & 528 & $9 \mathrm{e}^{-128}$ \\
\hline Saccharomyces cerevisiae & AAB68433.1 & 530 & $7 e-137$ \\
\hline Trichoderma reesei $\mathrm{QM6a}$ & EGR51226.1 & 526 & $6 \mathrm{e}^{-134}$ \\
\hline Ustilago maydis 521 & EAK84840.1 & 561 & $1 \mathrm{e}^{-169}$ \\
\hline
\end{tabular}


Table 2 - Primers used to amplify the Moniliophthora perniciosa ERG11 gene.

\begin{tabular}{lcc}
\hline Primer & Sequence (5' - 3') & First nucleotide position in M. perniciosa ERG11 cDNA (bp) \\
\hline LanFNcolfull (Forward) & ATGTCCCAtGgCGAAAACCTCAACGGTTC & 1 \\
LanFNheIfull (Forward) & CCTGTCATTGCtAgcGTACTCAATGTTCTCCG & 127 \\
LanFNheIdellahel (Forward) & GGCTCAGCTagcTCATACGGCAATGACCC & 223 \\
LanFNheIdel2ahel (Forward) & CTCTTTGcTaGcCGCGTCACTGTTGCC & 307 \\
LanRXhol (Reverse) & GCGTCTCCTcgAGTGAATACGTCTAGGCGT & 1591 \\
LanRNheI (Reverse) & GGCATCGTAATCATGcTAgcGTAGTTCTGAGC & 1627 \\
\hline
\end{tabular}

The variable temperatures used to amplify the genomic DNA were: $56^{\circ} \mathrm{C}$, (positions 1,6 and 11 ), $57.9^{\circ} \mathrm{C}$ (positions 2, 7 and 12 ), $60^{\circ} \mathrm{C}$ (positions 3,8 and 13 ), $62.7^{\circ} \mathrm{C}$ (positions 4, 9 and 14) and $64^{\circ} \mathrm{C}$ (positions 5, 10 and 15) (Figure 1). The temperatures used to amplify the cDNA were: $57.9^{\circ} \mathrm{C}$ (positions 1,5 and 9), $60{ }^{\circ} \mathrm{C}$ (positions 2, 6 and 10 ), $62.7^{\circ} \mathrm{C}$ (positions 3,7 and 11 ) and $64^{\circ} \mathrm{C}$ (positions 4, 8 and 12) (Figure 2).

The PCR products were visualized on $1 \%$ agarose gels containing ethidium bromide $(0.5 \mu \mathrm{g} / \mathrm{mL})$ and the gel was photographed using an EDAS 290 photodocumentation system (Kodak).

\section{Sequencing of PCR products}

The DNA and cDNA sequences that corresponded to ERG11 were confirmed by sequencing the purified PCR products on a MegaBACE 1000 capillary sequencer (Amersham Biosciences - GE Healthcare) using a DYEnamic ET dye terminator kit (GE Healthcare) according to the manufacturer's instructions.

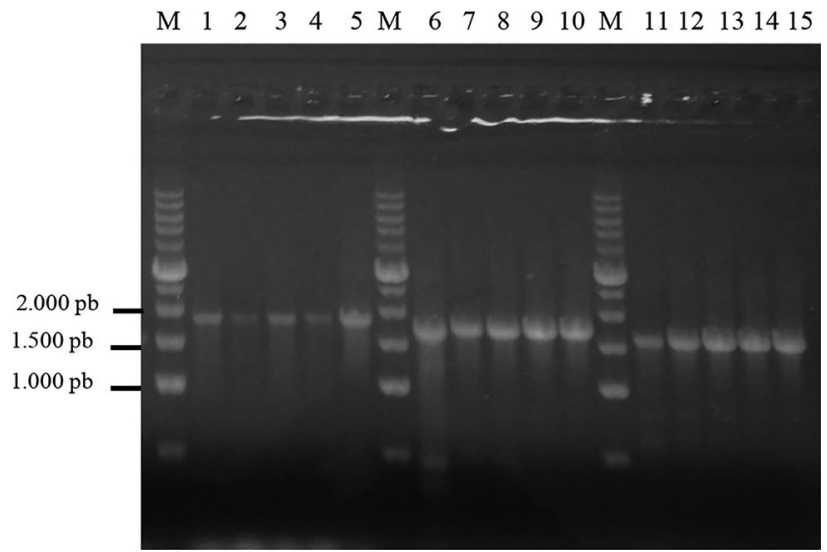

Figure 1 - Agarose gel electrophoresis of PCR products of Mper ERG11 amplified from genomic DNA. The reactions were done with an annealing temperature gradient. $\mathrm{M}$ - molecular weight marker (1 kb; Amresco). 1-5 genomic PCR products with no region corresponding to the signal peptide (1,858 bp), 6-10 - genomic PCR products without the first transmembrane insertion (1,712 bp), 11-15 - genomic PCR products without the first and second transmembrane insertions $(1,575 \mathrm{bp})$.

\section{Cloning of cDNA fragments of ERG11}

cDNA fragments of M. perniciosa ERG11 were cloned into the pET-28a vector (Novagen) and recombinant plasmids that contained the ERG11 gene were transformed in E. coli Rosetta (DE3) that were grown in LB medium ( $1 \%$ Tryptone, $1 \% \mathrm{NaCl}$ and $0.5 \%$ yeast extract) that contained appropriate antibiotics for selection. The identities of positive clones were confirmed by PCR and sequencing and were subsequently used for expression studies and the purification of lanosterol $14 \alpha$-demethylase.

\section{Sequence alignment and phylogenetic analysis}

Sequences obtained from the NCBI database (Table 1) and the predicted sequence from M. perniciosa were used to perform alignments with BioEdit (Hall, 1999) and ClustalW2 (Thompson et al., 1994) and a data matrix was used for the phylogenetic analyses. Twenty sequences were analyzed and Mycobacterium tuberculosis was used as an outgroup.

Maximum parsimony analysis (MP) was done with PAUP 4.0b10 software (Swofford, 2002) using Fitch parsimony (unordered characters and equal weighting) and branch-swapping heuristic search algorithms. The search

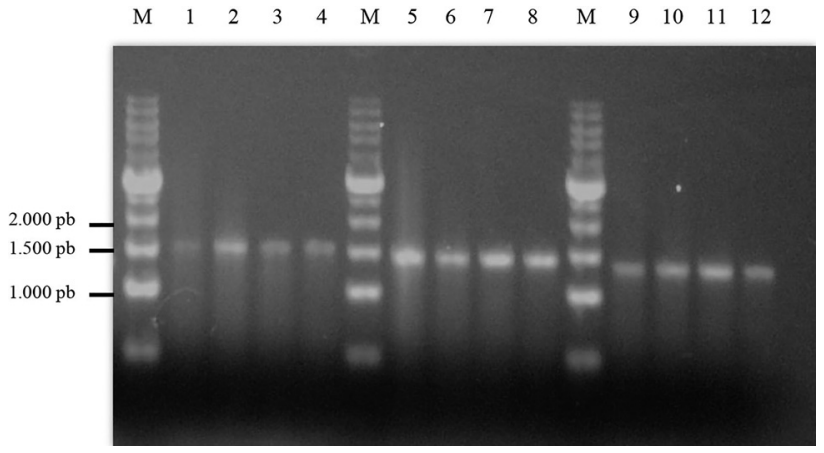

Figure 2 - Agarose gel electrophoresis of PCR products of ERG11 amplified from cDNA. The reactions were done with an annealing temperature gradient. M - molecular weight marker (1 kb; Amresco). 1 - cDNA products $(1,496 \mathrm{bp})$ with no region corresponding to the signal peptide, 5-8 cDNA products $(1,400 \mathrm{bp})$ without the first transmembrane insertion and 9-12 - cDNA products (1,316 bp) without the first and second transmembrane insertions. 
consisted of 1,000 replicates in which data were randomly added using the tree bisection and reconnection (TBR) algorithm; 15 trees per replicate were saved and all gaps were treated as missing data. A strict consensus tree was then obtained and the relative clade support was determined using the bootstrap - BS test (Felsenstein, 1985). Only values that were $\geq 75 \%$ are shown and the retrieved trees were edited using TreeView v.1.6 software (Page, 1996).

\section{Results}

\section{Isolation and characterization of the ERG11 gene in M. perniciosa}

The complete ERG11 gene that was amplified from genomic DNA contained 2,030 base pairs (bp) while the gene that was amplified from cDNA was 1,668 bp long. The gene product with no region corresponding to the signal peptide contained $1,858 \mathrm{bp}$ (Figure 1) while the product obtained by RT-PCR contained 1,496 bp (Figures 2 and S2).

Removal of the regions that corresponded to transmembrane insertions 1 and 2 generated genomic PCR products of $1,712 \mathrm{bp}$ and 1,575 bp, respectively (Figure 1) and cDNA products of 1,400 and 1,316 bp, respectively (Figure 2 ), as previously predicted by our bioinformatic analysis. The reliability of the DNA and cDNA base composition of ERG11 was confirmed by sequencing and demonstrated the accuracy of the gene prediction models that we used. Sequence analysis showed that $M$. perniciosa ERG11 has eight exons and seven introns (positions 166-215, 333-385, 509-561, 1027-1076, 1250-1301, 1771-1821 and 19151967).

Comparison of the lanosterol $14 \alpha$-demethylase amino acid sequence of $M$. perniciosa with those of other organisms indicated that it shared the greatest identity with the sequences of Coprinopsis cinerea (accession no. AAU01159.1) and Phanerochaete chrysosporium (AAU01160.1) (71\%), C. neoformans (AAF35366.1) and Cryptococcus gatti (AEQ63274.1) (57\%) and U. maydis (EAK84840.1) (55\%). Comparative analysis of the sequences yielded an E-value of 0.0 and the identity values exceeded the existing average of the amino acid sequences of CYP51 of lower eukaryotes (41\%) (Lepesheva and Waterman, 2007).

\section{Structural prediction and physicochemical parameters of lanosterol $14 \alpha$-demethylase}

Determination of the sequence of the ERG11 transcript allowed prediction of the primary structure of lanosterol 14 $\alpha$-demethylase, which consisted of 555 amino acids; the predicted molecular mass was $62 \mathrm{kDa}$ and the theoretical pI was 6.34. The ERG11 ORF in M. perniciosa exhibited two putative, highly hydrophobic transmembrane domains located near the $\mathrm{N}$-terminal region of the protein at amino acid positions $33-55$ and 62-84, which suggested a probable insertion in the endoplasmic reticulum membrane (Lepesheva and Waterman, 2007). In addition, signal peptide prediction identified a cleavage site between amino acid positions 46 and 47 and suggested that this protein was directed to the endoplasmic reticulum through the secretory pathway.

Analysis of CYP51 in $M$. perniciosa identified an iron-binding domain at amino acid positions 493-502 that is characteristic of proteins belonging to the cytochrome P450 superfamily.

\section{Sequence alignment and detection of conserved domains}

The alignment of ERG11 sequences from different organisms allowed the identification of several conserved domains that are characteristic of $\mathrm{P} 450$ proteins and, more specifically, of CYP51 proteins (EC 1.14.13.70). The $\mathrm{C}$-terminal region of these proteins contains a binding domain that is common to the heme group (FxxGxxxCxG). This domain was identified in M. perniciosa CYP51 and contained a conserved cysteine residue at amino acid position 500 that is responsible for the binding of iron to this protein (Figure 3). The SRS1 and SRS4 domains (substrate recognition regions) are relatively well conserved in CYP51.

The SRS1 (YxxF/L(I)xxPxFGxxVxF/YD/a) and SRS4 regions (GQ/hHT/sS) of $M$. perniciosa CYP51 were very similar to those of other organisms (Figure 3 ). The SRS1 region (B'helix/B'/loopC) forms the upper surface of the substrate binding cavity of P450 and the replacement of some conserved residues in this region can lead to partial or complete loss of CYP51 activity in Homo sapiens and Mycobacterium tuberculosis (Zhao et al., 2007). The SRS4 domain is located in the $\mathrm{C}$-terminal region of the P450 I-helix, which forms the right wall of the distal surface of the substrate binding cavity (Lepesheva and Waterman, 2007). The EXXR motif, which is characteristic of the K-helix of CYP51 (Kim et al., 2011), is also highly conserved (Figure 3).

\section{Phylogenetic analysis}

Phylogenetic analysis based on protein sequence data allowed assessment of the evolutionary relationships among CYP51 proteins of 20 organisms (Figure 4). Maximum parsimony analysis yielded three equally parsimonious trees, each with 2,700 steps (TreeBase access TB2:S14729). The maximum parsimony result was very similar to the maximum likelihood analysis (not shown), with the branches that clustered bacteria, fungi and animals being clearly distinct. The formation of these clusters agreed with the accepted phylogeny for the major kingdoms of organisms.

Species of the phylum Ascomycota were grouped in one clade and those belonging to the Basidiomycota were grouped in another (Figure 4). This sister group relation- 
ship for CYP51 phylogeny agreed with the general taxonomy of fungal species (James et al., 2006).

\section{Discussion}

Many of the genes that comprise the ergosterol biosynthetic pathway in M. perniciosa have been identified by genomic data mining. Our results indicate that the $M$. perniciosa genes that are part of this pathway show great similarity with those of the Basidiomycota, such as Coprinopsis cinerea (ERG1, ERG2, ERG9, ERG11, ERG24, ERG25 and ERG26), Laccaria bicolor (ERG5, ERG6 and ERG7) and Cryptococcus gatti (ERG4) (Martin et al., 2008; Stajich et al., 2010; D’Souza et al., 2011). These data demonstrate the conservation of genes and biosynthetic pathways that are essential for the survival of related organisms.

The biosynthetic pathways for ergosterol and steroids have been studied mostly in model organisms such as Kluveromyces lactis and Saccharomyces cerevisiae, and in those that cause public health problems, such as Aspergillus fumigatus, Candida albicans, C. dubliniensis, C. glabrata and C. tropicalis (Goffeau et al., 1996; Dujon et al., 2004; Jones et al., 2004; Nierman et al., 2005; Butler et al., 2009). However, there is little information on the steroid bio-

\section{SRS1}

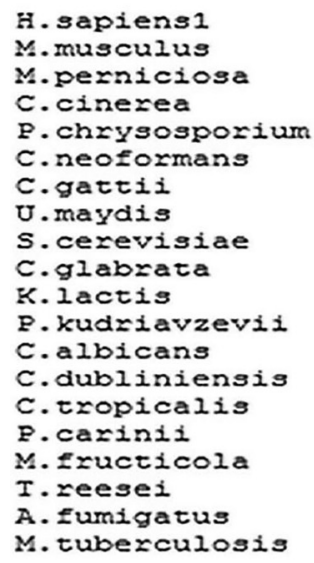

\begin{tabular}{|c|c|c|c|}
\hline & & & \\
\hline AIIFNSKANEDINAEE & YGRIITPVEGKGVAYD & IFLEQKKIIKSGLNIAHEKQYVPI & 27 \\
\hline NEILGGKSTVFSAEE & YTHLTTPY & INEVFMEQKRFVRVGLSTENLRAYVGM & 17 \\
\hline NEILGGKSIVFIAED: & YIHLIIPVEGKDVVYD & INEKFMQQKREIKAGISIENLRAYVGM & 25 \\
\hline NFIMGGKHTTFSAEE & $---\operatorname{LTTPV}$ & NELLMEQKKFVKFGLSTENFRQYVGM & 14 \\
\hline NLSIGGKISQVSAEE & YIHIITPVFGKGVVYD & NEMLMQQKKFIKSGLITESLQSYPPM & 1 \\
\hline NLSLGGKISQVSAE & YT: & MQQKKFIKSGITTESLQSYPPM & 1 \\
\hline NLVFNAKHQQVIAE & YTIHITIPVEGKEVVYDV: & INAVFMEQKRKVRVGLSIENFRVYVPQ & 17 \\
\hline EFVFNAKLADVSAEA & YAHLTTP & NSRLMEQKKFVKGAITKEAFKSYVPL & 16 \\
\hline EFIFNARLADVSAEAU & YSHITIPVEGKGVIYDC: & INHRIMEQKRFVKGAITKEAFVRYVPI & 17 \\
\hline EFILNAKLADVSAEA & YYTHLTTPV & NHRLMDQKKEVKGAITTDAFRKYVPL & 170 \\
\hline EFVLNAKLSDVSA & YTHLITP & INWKLMEQKKFAKVAITKESFIRYVPL & 9 \\
\hline EFVFNAKLSDVSA & YKH & INSRLMEQKKFAKFAITIDSFKRYVPK & 161 \\
\hline EFIFNAKLSDVSF & YYKF & INSRLMEQKKFAKFAIITESFKRYVPK & 61 \\
\hline EFIYNAKLSDVSAEE & YTHLTIPY & INSRLMEQKKFAKFAIITDSFKIYVPK & 161 \\
\hline DIIFNGKLSSISA & YT: & INHVLMEQKRFVITGFIIETFRAYVPI & 58 \\
\hline DEILNGKHKDII & YTV & NAKLMEQKKFMKIGISTE & 65 \\
\hline DEIINGKLKDVNA & YSV & NAKLMEQKKFMKIAITTEAF & 0 \\
\hline EFIINGKLKDVN & YSPLITPV & INSKLLMEQKKFIKYGLIQSAL & 50 \\
\hline E] & EMTI & ILHNAALRGEQMR & 11 \\
\hline & $: \star \star: \star \star$ & $:: \quad:$ & \\
\hline
\end{tabular}

--KIDDILQILIDATYKDGRP-IID PEVAGMLIGLILAGQHISSTISAWMGFFLARDKTI 339 --PAEDILQTIIDSTYKDGRP-LTDEEISGMLIGLILAGQHISSTISAWMGFFLAKDKPI 333 -DYDQDMIEAIMEQKYRSGKG-LKD HEIAHIMIAILMAGQHISSA FGSWALIHLADNPDI 347 -EVEHDMIASISEQRYRSGAP-IPD FEIAHIMIAIIMAGQHISSAPSSWALIHLAHNVEV 322 -EEEHDMIAAIMNQKYRVGRP-LKD FEIAHIMIAILMAGQHTSSA FGSWALIHIADRPDV 316 -DHEHDMIENLQSCKYRNGVP-LSD RDIAHIMIAIIMAGQHISSA ISSWILIHLADRPDV 339 -DHEHDMIENLQGCKYRNGVP-LSD RDVAHIMIAIIMAGQHISSATSSWTIIHLADRPDV 339 ASGENDMIAAIIEQKYKNGRA-LSG FEIAHMIIILMAGQHISSA FSSWAFLRLASRPEI 347 --DRDLIDSLMKNSTYKDGVK-MID DEIANLIIGVLMGGQHISAATSAWILIHLAERPDV 336 --NRDI IDELMRNSTYKDGTK-MT DE IANLI I GVLMGGQHTSAA TSANCLLHLAERPDV 337 --DRDLIDSLMKNSTYKDGVK-MI DEIANLI I GVLWGGQHISAAFSAWVILHLAERPDI 337 --NEDLVDALIKNSVYKDGTR-MTDEIAHLMIGVLMGGQHTSSA F SAWFLIHLGEKFQI 331 --NRDIIDSLIIHSTYKDGVK-MTDEEIANLIIGILMGGOHTSAS TSAWFLIHLGEKPHL 329 --SRDIIDSIITHSTYKDGVK-MID REIANLIIGILMGGQHISAS YSAWFLIHLGEKPHI 329 --KRDI IDSILVNSTYKDGVK-MTD REIANLI I VVLMGSQHTSAS F SANFLIHLAEQFQI 329 --EKDMINNLMN-QHYKDGRK-IID KEIAHLMIAIIMAGQHISAA FGCTWILHLAEKPEY 323 --FKSDIMNQLMRSSYKDGTP-VPD KEIANMMIAILMAGQHSSSS ISWIMLRLAARPDI 330 --KEIDILKHLMTSVYKDGTP-VPD HEIAHMMIAILMAGQHSSSS ISSWIMLRLAQY PHV 330 --QKSDMIWNLMNCIYKANGQ-VPD KEIAHMMITIIMAGQHSSSS ISAWIMIRLASQPKV 315 --SDRDMLDVIIAVRAETGT PRFSA PEITGMFISMMFAGHHTSSG TASWTIIELMRHRDA 278 $\left.: \quad: *^{\star} \cdot{ }^{*}::::^{\star}::::^{\star}::^{\star}:\right]^{\star}:$ :

\section{SRS4}

Figure 3 - Moniliophthora perniciosa CYP51 alignment with other homologous CYP51 sequences. Conserved amino acid residues that correspond to the heme-binding site (HBR), substrate recognition sites (SRS1 and SRS4) and EXXR motifs are shown in boxes. The arrow indicates the conserved cysteine residue. Homo sapiens 1 - H. sapiens isoform 1 (NP_0000777.1), Mus musculus - Mus musculus (NP_064394.2), Moniliophthora perniciosa Moniliophthora perniciosa (JX915631), Coprinopsis cinerea - Coprinopsis cinerea (AAU01159.1), Phanerochaete chrysosporium - Phanerochaete chrysosporium (AAU01160.1), Cryptococcus neoformans - Cryptococcus neoformans var. neoformans (AAF35366.1), C. gattii - Cryptococcus gattii (AEQ63274.1), Ustilago maydis - Ustilago maydis 521 (EAK84840.1), Saccharomyces cerevisiae - Saccharomyces cerevisiae (AAB68433.1), Candida glabrata, Candida glabrata (AAX39317.1), Kluveromyces lactis, Kluveromyces lactis (CAG99196.1), Pichia kudriavzevii - Pichia kudriavzevii (ABY26735.1), Candida albicans - Candida albicans (AAF00603.1), Candida dubliniensis - Candida dubliniensis CD36 (CAX41448.1), Candida tropicalis - Candida tropicalis (AAX39316.1), Pneumocystis carinii - Pneumocystis carinii (AAO38776.1), Monilinia fructicola - Monilinia fructicola (ACF06200.1), Trichoderma reesei - Trichoderma reesei QM6a (EGR51226.1), Aspergillus fumigatus - Aspergillus fumigatus (ACF17705.1), Mycobacterium tuberculosis - Mycobacterium tuberculosis (CAB02394.1). 


\author{
H. sapiens1 \\ M.musculus \\ M.perniciosa \\ c. cinerea \\ P. chrysosporium \\ C. neoformans \\ c.gateii \\ U.maydis \\ S. cerevisiae \\ C.glabrata \\ K.lactis \\ P. kudriavzevii \\ C. albicans \\ c. dubliniensis \\ c. tropicalis \\ P. carinii \\ M. Eructicola \\ I. reesei \\ A. fumigarus \\ M. tuberculosis
}

\author{
H. sapiens1 \\ M.musculus \\ M.perniciosa \\ C. cinerea \\ P. chrysosporium \\ c.neoformans \\ C.gatrii \\ U.maydis \\ S.cerevisiae \\ C.glabrata \\ K. lactis \\ P. kudriavzevii \\ C.albicans \\ C.dubliniensis \\ c. Tropicalis \\ P.carinii \\ M. Exucticola \\ I. reesei \\ A. Eumigatus \\ M. tuberculosis
}
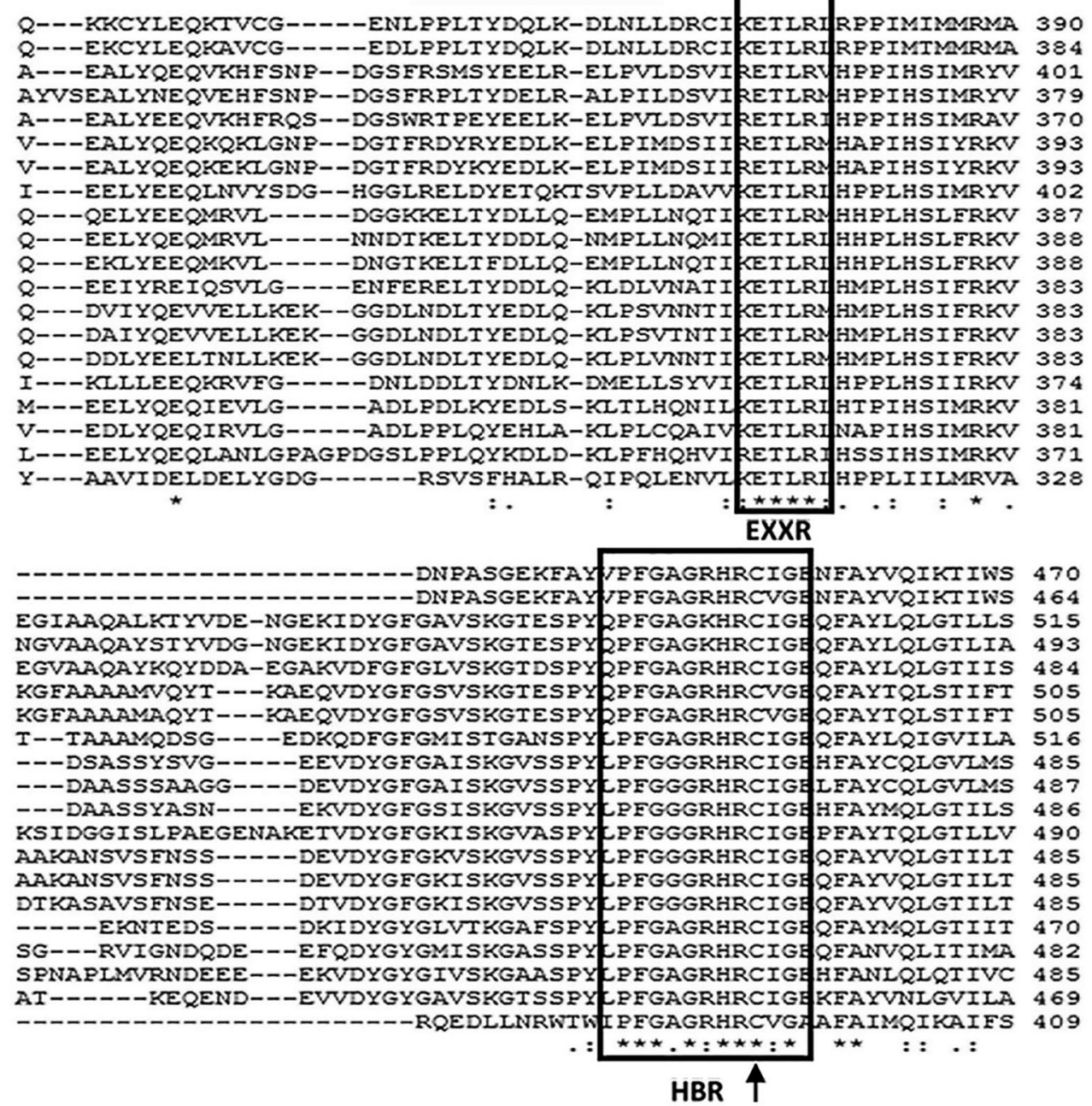

Figure 3 cont. -

synthetic pathways of phytopathogenic filamentous fungi (except for $A$. fumigatus). Gaps in our knowledge concerning the genes of this pathway in some organisms reflect a lack of genomic data or the need for further studies related to sequences that have already been deposited in genomic databases and EST libraries. The results of the present study fill a gap in our knowledge of this metabolic pathway. This pathway is particularly important for the development of M. perniciosa and may be useful in designing new antifungal drugs.

The detection of ERG11 gene expression during the mycelial stage of $M$. perniciosa, as shown here, suggests that mycelial development requires intense steroidal activity. ERG11 is highly expressed since ergosterol is an essential sterol. Ergosterol is the major component of the fungal cell membrane and is essential as a bioregulator of membrane fluidity, asymmetry and integrity (Barrett-Bee and Dixon, 1995; Carrilo-Muñoz et al., 2006). The membranes of eukaryotic cells act as barriers between the inside of the cell or the lumen of organelles and the corresponding exter- nal environment. These membranes also contain proteins that selectively transport molecules or act as enzymes in different metabolic activities (Veen and Lang, 2005).

Macroarray analysis of the differential expression of ERG11 during $M$. perniciosa development, which was part of effort to construct a cDNA library for M. perniciosa, indicated that this gene was hyperexpressed during the white mycelial stage and had a lower level of expression during the primordial stage, prior to the formation of basidiomata (Pires et al., 2009). This finding indicated that expression levels of this gene vary during fungal development.

The strong conservation of regions SRS1, SRS4 and the EXXR motif of lanosterol $14 \alpha$-demethylases among organisms belonging to different groups indicated their importance in the recognition of basal substrates. Despite the variability among CYP51 sequences, the basic structure of this protein needs to be maintained in order to retain its catalytic activity, and this structure is determined by the HBR and the more conserved substrate recognition sites (SRS1 and SRS4) (Lepesheva and Waterman, 2007; Zhao et al., 


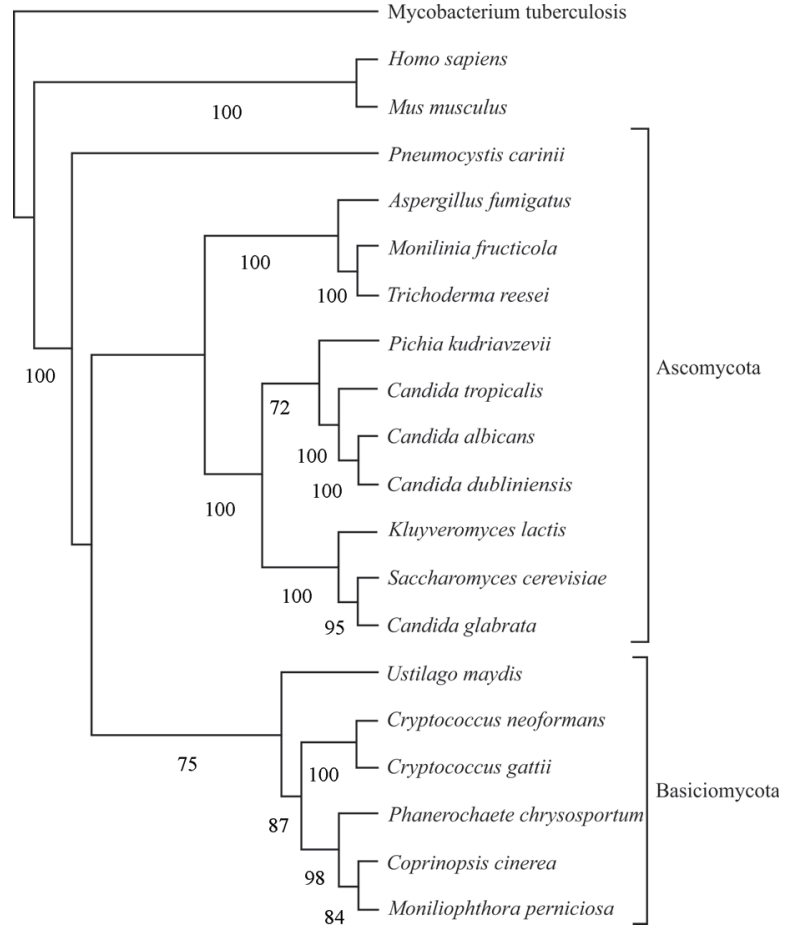

Figure 4 - The most parsimonious tree obtained from the Maximum Parsimony analysis based on the amino acid sequence of lanosterol $14 \alpha$-demethylase. The numbers below the branches indicate bootstrap support (in $\%$ ). Length: 2,700 steps.

2007). These CYP51 regions are conserved in fungi from different phyla (Figure 3). The identity between the CYP51 sequences and the low E-values (Table 1) were indicators of the high similarity between the CYP51 orthologs of these phylogenetically related organisms.

As with M. perniciosa, introns have also be observed in the homologous sequences of other basidiomycetes such as C. cinerea, C. neoformans and P. chrysosporium, that contain six, eight and six introns, respectively (Mellado et al., 2001; Revankar et al., 2004; Warrilow et al., 2010). Ustilago maydis is the only Basidiomycete that lacks introns in the ERG11 gene (Revankar et al., 2004). Furthermore, introns are usually not found in Ascomycota such as C. albicans, $P$. carinni and S. cerevisiae. The average size of the ERG11 introns in M. perniciosa was $52 \mathrm{bp}$, as estimated for other genes analyzed by genome sequencing (Mondego et al., 2008). In contrast to the positional variation of ERG11 introns among organisms that may reflect evolutionary events in the P450 superfamily, the HBR, which is highly conserved in this family of proteins, has not suffered recombination events or exon shuffling (Rozman et al., 1996).

In phylogenetic analysis, the formation of welldefined clusters confirmed the accepted phylogeny for the major kingdoms of organisms. Fungi formed two distinct clades. The organisms that showed higher identity values with the CYP51 sequences of $M$. perniciosa (C. cinerea, $P$. chrysosporium, C. gattii, C. neorformans and U. maydis) formed a distinct clade that included M. perniciosa and had a significant bootstrap value (Figure 4); this finding indicates that Mper ERG11 is phylogenetically closer to $C$. cinerea ERG11 than to all homologs of the other Basidiomycota with well-characterized sequences.

The cloning of M. perniciosa CYP51 in expression vectors will enable the recombinant production of lanosterol $14 \alpha$-demethylase and should provide sufficient protein for elucidation of the structure of this enzyme. A similar approach applied to other enzymes in this pathway should contribute to the design and optimization of more effective drugs against this phytopathogenic fungus.

\section{Acknowledgments}

We thank Financiadora de Estudos e Projetos (FINEP) and Fundação de Amparo à Pesquisa do Estado da Bahia (FAPESB) for financial support and the Postgraduate Program in Biotechnology (PPGBiotec) at UEFS/FIOCRUZ for student support. This work is dedicated to the late Dr. Júlio Cézar de Mattos Cascardo.

\section{References}

Aime MC and Phillips-Mora W (2005) The causal agents of witches' broom and frost pod rot of cacao (chocolate, Theobroma cacao) from a new lineage of Marasmiaceae. Mycologia 97:1012-1022.

Albertini C, Thebaud G, Fournier E and Leroux P (2002) Eburicol $14 \alpha$-demethylase gene (CYP51) polymorphism and speciation in Botrytis cinerea. Mycol Res 106:1171-1178.

Altschul SF, Gish W, Miller W, Myers EW and Lipman DJ (1990) Basic local alignment search tool. J Mol Biol 215:403-410.

Bak S, Kahn RA, Oisen CE and Halkier BA (1997) Cloning and expression in Escherichia coli of the obtusifoliol $14 \alpha$-demethylase of Sorghum bicolor (L.) Moench, a cytochrome P450 orthologous to the sterol $14 \alpha$ demethylases (CYP51) from fungi and mammals. Plant J 11:191-201.

Barrett-Bee K and Dixon G (1995) Ergosterol biosynthesis inhibition: A target for antifungal agents. Acta Biochim Pol 42:465-480.

Bellamine A, Mangla AT, Nes WD and Waterman MR (1999) Characterization and catalytic properties of the sterol $14 \alpha$-demethylase from Mycobacterium tuberculosis. Proc Natl Acad Sci USA 96:8937-8942.

Butler G, Rasmussen MD, Lin MF, Santos MA, Sakthikumar S, Munro CA, Rheinbay E, Grabherr M, Forche A, Reedy JL, et al. (2009) Evolution of pathogenicity and sexual reproduction in eight Candida genomes. Nature 459:657-662.

Carrillo-Muñoz AJ, Giusiano G, Ezkurra PA and Quindós G (2006) Antifungal agents: Mode of action in yeast cells. Rev Esp Quim 19:130-139.

Ceita GO, Macedo JN, Santos TB, Alemanno L, Gesteira AS, Micheli F, Mariano AC, Gramacho KP, Silva DC, Meinhardt LW, et al. (2007) Involvement of calcium oxalate degradation during programmed cell death in Theobroma cacao tissues triggered by the hemibiotrophic fungus Moniliophthora perniciosa. Plant Sci 173:106-117. 
D'Souza CA, Kronstad JW, Taylor G, Warren R, Yuen M, Hu G, Jung WH, Sham A, Kidd SE, Tangen K, et al. (2011) Genome variation in Cryptococcus gattii, an emerging pathogen of immunocompetent hosts. MBio 2:e00342-10.

Délye C, Laigret F and Corio-Costet MF (1997) Cloning and sequence analysis of the eburicol $14 \alpha$-demethylase gene of the obligate biotrophic grape powdery mildew fungus. Gene 195:29-33.

Dujon B, Sherman D, Fischer G, Durrens P, Casaregola S, Lafontaine I, De Montigny J, Marck C, Neuvéglise C, Talla E et al. (2004) Genome evolution in yeasts. Nature 430:35-44.

Evans HC (2007) Cacao diseases - The trilogy revisited. Phytopathology 97:1640-1643.

Felsenstein J (1985) Confidence limits on phylogenies: An approach using the bootstrap. Evolution 39:783-791.

Formighieri EF, Tiburcio RA, Armas ED, Medrano FJ, Shimo H, Carels N, Góes Neto A, Cotomacci C, Carazzolle MF, Sardinha-Pinto N, et al. (2008) The mitochondrial genome of the phytopathogenic basidiomycete Moniliophthora perniciosa is $109 \mathrm{~kb}$ in size and contains a stable integrated plasmid. Mycol Res 112:1136-1152.

Gasteiger E, Hoogland C, Gattiker A, Duvaud S, Wilkins MR, Appel RD and Bairoch A (2005) Protein identification and analysis tools on the ExPASy Server. In: Walker JM (ed) The Proteomics and Protocols Handbook. Humana Press, Totowa, pp 571-607.

Goffeau A, Barrell BG, Bussey H, Davis RW, Dujon B, Feldmann H, Galibert F, Hoheisel JD, Jacq C, Johnston M, et al. (1996) Life with 6000 genes. Science 265:2077-2082.

Griffith GW, Bravo-Velasquez E, Wilson FJ, Lewis DM and Hedger JN (1994) Autecology and evolution of the witches' broom pathogen (Crinipellis perniciosa) of cocoa. In: Blakeman JP and Williamson B (eds) The Ecology of Plant Pathogens. CAB International, Wallingford, pp 245-265.

Griffith GW, Nicholson J, Neinninger A and Birch R (2003) Witches' brooms and frosty pods: Two major pathogens of cacao. New Zeal J Bot 41:423-435.

Hall TA (1999) BioEdit: A user-friendly biological sequence alignment editor and analysis program for Windows 95/98/NT. Nucleic Acids Res 41:95-98.

Hof H (2001) Critical annotations to the use of azole antifungals for plant protection. Antimicrob Agents Chemother 45:2987-2990.

Jackson CJ, Lamb DC, Marczylo TH, Parker JE, Manning NL, Kelly DE and Kelly SL (2003) Conservation and cloning of CYP51: A sterol 14 $\alpha$-demethylase from Mycobacterium smegmatis. Biochem Biophys Res Commun 301:558-563.

James TY, Kauff F, Schoch CL, Matheny PB, Hofstetter V, Cox CJ, Celio G, Gueidan C, Fraker E, Miadlikowska J, et al. (2006) Reconstructing the early evolution of Fungi using a six-gene phylogeny. Nature 19:818-822.

Jones T, Federspiel NA, Chibana H, Dungan J, Kalman S, Magee BB, Newport G, Thorstenson YR, Agabian N, Magee PT, et al. (2004) The diploid genome sequence of Candida albicans. Proc Natl Acad Sci USA 101:7329-7334.

Kairuz PB, Zuber JP, Jaunin P, Buchman TG, Bille J and Rossier M (1994) Rapid detection and identification of Candida albicans and Torulopsis (Candida) glabrata in clinical specimens by species-specific nested PCR amplification of a cytochrome P-450 lanosterol- $\alpha$-demethylase (L1A1) gene fragment. J Clin Microbiol 32:1902-1907.
Kalb VF, Woods CW, Turi TG, Dey CR, Sutter TR and Loper JC (1987) Primary structure of the P450 lanosterol demethylase gene from Saccharomyces cerevisiae. DNA 6:529-537.

Kall L, Krogh A and Sonnhammer EL (2007) Advantages of combined transmembrane topology and signal peptide prediction- the Phobius web server. Nucleic Acids Res 35:429432.

Kim D, Lim YR, Ohk SO, Kim BJ and Chun YJ (2011) Functional expression and characterization of CYP51 from dandruffcausing Malassezia globosa. FEMS Yeast Res 11:80-87.

Lai MH and Kirsch DR (1989) Nucleotide sequence of cytochrome P450 L1A1 (lanosterol 14 $\alpha$-demethylase) from Candida albicans. Nucleic Acids Res 17:804.

Lamb DC, Kelly DE, Manning NM, Hollomon DW and Kelly SL (1998) Expression, purification, reconstitution and inhibi-

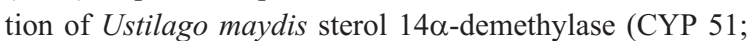
P450). FEMS Microbiol Lett 169:369-373.

Lee CH, Hsu KH, Wang SY, Chang TT, Chu FH and Shaw JF (2010) Cloning and characterization of the lanosterol $14 \alpha$-demethylase gene from Antrodia cinnamomea. J Agr Food Chem 58:4800-4807.

Lees ND, Skaggs B, Kirsch DR and Bird M (1995) Cloning of the late genes in the ergosterol biosynthetic pathway of Saccharomyces cerevisiae - A review. Lipids 30:221-226.

Lepesheva GI and Waterman MR (2007) Sterol 14 $\alpha$-demethylase cytochrome P450 (CYP51), a P450 in all biological kingdoms. Biochim Biophys Acta 3:467-477.

Luo CX and Schnabel G (2008) The cytochrome P450 lanosterol $14 \alpha$-demethylase gene is a demethylation inhibitor fungicide resistance determinant in Monilia fructicola field isolates from Georgia. Appl Environ Microb 74:359-366.

Martin F, Aerts A, Ahrén D, Brun A, Danchin EG, Duchaussoy F, Gibon J, Kohler A, Lindquist E, Pereda V, et al. (2008) The genome of Laccaria bicolor provides insights into mycorrhizal symbiosis. Nature 452:88-92.

McQuilken MP and Rudgard SA (1988) Sensitivity of Crinipellis periciosa to two triazole fungicides in vitro and their effect on development of the fungus in cocoa. Plant Pathol 37:499-506.

Meinhardt LW, Bellato CM, Rincones J, Azevedo RA, Cascardo JCM and Pereira GAG (2006) In vitro production of biotrophic-like cultures of Crinipellis perniciosa, the causal agent of Witches' broom disease of Theobroma cacao. Curr Microbiol 52:191-196.

Mellado E, Guerra TMD, Estrela MC and Tudela JLR (2001) Identification of two different $14 \alpha$-sterol demethylase related genes (cyp51A and cyp51B) in Aspergillus fumigatus and other Aspergillus species. J Clin Microbiol 39:24312438.

Mondego JMC, Carazzolle MF, Costa GGL, Formighieri EF, Parizzi LP, Rincones J, Cotomacci C, Carraro DM, Cunha AF, Carrer H, et al. (2008) A genome survey of Moniliophthora perniciosa gives new insights into Witches' broom disease of cacao. BMC Genomics 9:1-25.

Morales IJ, Vohra PK, Puri V, Kottom TJ, Limper AH and Thomas CF (2003) Characterization of a lanosterol $14 \alpha$ demethylase from Pneumocystis carinii. Am J Resp Cell Mol 29:232-238.

Mota SGR, Barros TF and Castilho MS (2010) In vitro screening and chemometrics analysis on a series of azole derivatives 
with fungicide activity against Moniliophthora perniciosa. J Braz Chem Soc 21:510-519.

Nierman WC, Pain A, Anderson MJ, Wortman JR, Kim HS, Arroyo J, Berriman $\mathrm{M}$, Abe $\mathrm{K}$, Archer $\mathrm{DB}$, Bermejo C, et al. (2005) Genomic sequence of the pathogenic and allergenic filamentous fungus Aspergillus fumigatus. Nature 438:1151-1156.

Page RDM (1996) TREEVIEW: An application to display phylogenetic trees on personal computers. Comput Appl Biosci 12:357-358.

Park HG, Lee IS, Chun YJ, Yun CH, Johnston JB, Montellano PRO and Kim D (2011) Heterologous expression and characterization of the sterol $14 \alpha$-demethylase CYP51F from Candida albicans. Arch Biochem Biophys 509:9-15.

Pereira JL, Ram A, Figueiredo JM and Almeida LCC (1989) Primeira ocorrência de vassoura-de-bruxa na principal região produtora de cacau do Brasil. Agrotrópica 1:79-81.

Petersen TN, Brunak S, Heijne G and Nielsen H (2011) SignalIP 4.0: Discriminating signal peptides from transmembrane regions. Nat Methods 10:785-786.

Pietila MP, Vohra PK, Sanyat B, Wengenack NL, Raghavakaimal $\mathrm{S}$ and Thomas CF (2006) Cloning and characterization of CYP51 from Mycobacterium avium. Am J Resp Cell Mol 35:236-240.

Pires ABL, Gramacho KP, Silva DC, Góes-Neto A, Silva MM, Muniz-Sobrinho JS, Porto RF, Villela-Dias C, Brendel M, Cascardo JCM, et al. (2009) Early development of Moniliophthora perniciosa basidiomata and developmentally regulated genes. BMC Microbiol 9:e158.

Purdy LH and Schimidt RA (1996) Status of cacao witches' broom: Biology, epidemiology, and management. Annu Rev Phytopathol 34:573-594.

Raeder U and Broda P (1985) Rapid preparation of DNA from filamentous fungi. Lett Appl Microbiol 1:17-20.

Revankar SG, Fu J, Rinaldi MG, Kelly SL, Kelly DE, Lamb DC, Keller SM and Wickes BL (2004) Cloning and characterization of the lanosterol $14 \alpha$-demethylase $(E R G 11)$ gene in Cryptococcus neoformans. Biochem Biophys Res Commun 324:719-728.

Rincones J, Scarpari LM, Carazzolle MF, Mondego JMC, Formighieri, EF, Barau JG, Costa GGL, Carraro DM, Brentani HP, Vilas-Boas LA, et al. (2008) Differential gene expression between the biotrophic-like and saprotrophic mycelia of the witches' broom pathogen Moniliophthora perniciosa. Mol Plant Microbe Int 21:891-908.

Rio MCS, Oliveira BV, Tomazella DPT, Silva JAF and Pereira GAG (2008) Production of calcium oxalate crystals by the basidiomycete Moniliophthora perniciosa, the causal agent of witches' broom disease of cacao. Curr Microbiol 56:363370 .

Rozman D, Stromstedt M, Tsui LC, Scherer SW and Waterman MR (1996) Structure and mapping of the human lanosterol $14 \alpha$-demethylase gene (CYP51) encoding the cytochrome P450 involved in cholesterol biosynthesis: Comparison of exon/intron organization with other mammalian and fungal CYP genes. Genomics 38:371-381.

Sheng C, Miao Z, Ji H, Yao J, Wang W, Che X, Dong G, Lu J, Guo W and Zhang W (2009) Three-dimensional model of lanosterol 14 $\alpha$-demethylase from Cryptococcus neoformans: Active-site characterization and insights into azole binding. Antimicrob Agents Chemother 53:3487-3495.
Sigrist CJA, Cerutti L, Castro E, Langendijk-Genevaux PS, Bulliard V, Bairoch A and Hulo N (2009) PROSITE, a protein domain database for functional characterization and annotation. Nucleic Acids Res 38:161-166.

Stajich JE, Wilke SK, Ahrén D, Au CH, Birren BW, Borodovsky M, Burns C, Canback B, Casselton LA, Cheng CK, et al. (2010) Insights into evolution of multicellular fungi from the assembled chromosomes of the mushroom Coprinopsis cinerea (Coprinus cinereus). Proc Natl Acad Sci USA 107:11889-11894.

Stanke M, Keller O, Gunduz I, Hayes A, Waack S and Morgenstern B (2006) AUGUSTUS: Ab initio prediction of alternative transcripts. Nucleic Acids Res 34:435-439.

Swofford DL (2002) PAUP - Phylogenetic Analysis Using Parsimony (and other methods). Version 4.0b10. Sinauer Associates, Sunderland, MA.

Ter-Hovhannisyan V, Lomsadze L, Chernoff YO and Borodovsky M (2008) Gene prediction in novel fungal genomes using an ab initio algorithm with unsupervised training. Genome Res 18:1979-1990.

Thompson JD, Higgins DG and Gibson TJ (1994) CLUSTAL W: Improving the sensitivity of progressive multiple sequence alignment through sequence weighting, position specific gap penalties and weigh matrix choice. Nucleic Acids Res 22:4673-4680.

Veen $M$ and Lang C (2005) Interactions of the ergosterol biosynthetic pathway with other lipid pathways. Biochem Soc Trans 33:1178-1181.

Warrilow AGS, Melo N, Martel CM, Parker JE, Nes WD, Kelly SL and Kelly DE (2010) Expression, purification and characterization of Aspergillus fumigatus sterol $14 \alpha$ demethylase (CYP51) isoenzymes A and B. Antimicrob Agents Chemother 54:4225-4234.

Waterman MR and Lepesheva GI (2005) Sterol $14 \alpha$-demethylase, an abundant and essential mixed-function oxidase. Biochem Biophys Res Commun 338:418-422.

Wood HM, Dickinson MJ, Lucas JA and Dyer PS (2001) Cloning of the CYP51 gene from the eyespot pathogen Tapesia yallundae indicates that resistance to the DMI fungicide prochloraz is not related to sequence changes in the gene encoding the target site enzyme. FEMS Microbiol Lett 196:183-187.

Zhao L, Liu D, Zhang Q, Zhang S, Wan J and Xiao W (2007) Expression and homology modeling of sterol $14 \alpha$-demethylase from Penicillium digitatium. FEMS Microbiol Lett 277:37-43.

\section{Internet Resources}

AUGUSTUS software, http://augustus.gobics.de (11 Jan 2012).

GeneMark, http://exon.biology.gatech.edu/ (11 Jan 2012). SignalIP 4.0 software, http://www.cbs.dtu.dk/services/SignalP/ (11 Jan 2012).

Phobius program, http://www.ebi.ac.uk/Tools/pfa/phobius/ (11 Jan 2012). ProtoParam tool, http://web.expasy.org/protparam/ (11 Jan 2012).

PROSITE software, http://prosite.expasy.org/ (11 Jan 2012). 


\section{Supplementary Material}

The following online material is available for this article:

Figure S1 - Positions of the primers used to amplify the DNA sequences.

Figure S2 - Nucleotide and amino acid sequence of the ERG11 gene of M.
The material is available as part of the online article from http://www.scielo.br/gmb.

Associate Editor: Célia Maria de Almeida Soares

License information: This is an open-access article distributed under the terms of the Creative Commons Attribution License, which permits unrestricted use, distribution, and reproduction in any medium, provided the original work is properly cited. 